This case serves as a timely reminder of the importance of sterile and no touch techniques when dealing with undiagnosed infection, and that women who book late are an unusual group and all investigations on them should be processed urgently.

We thank Dr N Johnston of the Venereal Disease Reference Laboratory who made the diagnosis of syphilis by examining the ascitic fluid, and the nursing, paediatric, and venereological colleagues who helped to care for the patient and her baby.

1 Anonymous. Communicable diseases report 1981;47, 27 November:3.

${ }^{2}$ Harter CS, Benirschke K. Fetal syphilis in the first trimester. Am $\mathcal{F}$ Obstet Gynecol 1976;124:705-11.

(Accepted 11 August 1982)

Department of Obstetrics and Gynaecology, London Hospital Medical College, London E1 2AD

WENDY D SAVAGE, MRCOG, senior lecturer

FRANCES READER, MRCOG, registrar

\section{Benoxaprofen: effect on cutaneous lesions in psoriasis}

Benoxaprofen is an anti-inflammatory drug that is as effective an inhibitor of inflammation experimentally as indomethacin and phenylbutazone. ${ }^{1}$ It has little effect on prostaglandin synthesis but does appear to inhibit lipoxygenase activity ${ }^{2}$ and modify inflammatory cell function. Our interest in the drug was stimulated by the chance finding that the skin lesions in a patient with arthritis and psoriasis cleared shortly after the drug was started. We conducted a small pilot study in 13 patients.

\section{Patients, methods, and results}

The 13 patients selected for the study were attending our department with severe psoriasis that had failed to respond to standard measures, including, in most cases, cytotoxic drugs. All other treatment was withdrawn for four weeks before benoxaprofen was introduced in a dose of $600 \mathrm{mg}$ daily. Treatment was on an open basis and the drug was continued for at least four to eight weeks. The table summarises clinical details.

Of the 13 patients treated the psoriasis was unchanged in five, greatly improved in four, and cleared in four. In two of the four whose psoriasis was cleared (cases 2 and 8 ) treatment was discontinued after eight weeks: one patient (case 8 ) has remained free from trouble, but the other (case 2) suffered a further attack after five months without treatment; this was brought rapidly under control with a further course of benoxaprofen. In the other two patients (cases 5 and 10) the drug has been continued. A fifth patient (case 4) greatly improved with treatment and her psoriasis would almost certainly have cleared had she not discontinued treatment because of dyspepsia.

\section{Comment}

It is most unlikely, given the severity of the condition, that the improvement was spontaneous: thus, eight out of 13 patients benefited

Details of 13 patients treated for psoriasis with benoxaprofen

\begin{tabular}{cccccl}
\hline $\begin{array}{c}\text { Case } \\
\text { No }\end{array}$ & Sex & Age & $\begin{array}{c}\text { Duration of } \\
\text { psoriasis } \\
\text { (years) }\end{array}$ & $\begin{array}{c}\text { Extent of } \\
\text { lesions } \\
(\%)\end{array}$ & Response \\
\hline 1 & $\mathrm{~F}$ & 71 & 21 & 30 & No change \\
2 & $\mathrm{M}$ & 21 & 14 & 50 & Cleared \\
3 & $\mathrm{~F}$ & 35 & 15 & 50 & Improved \\
4 & $\mathrm{~F}$ & 66 & 30 & 90 & Improved \\
5 & $\mathrm{M}$ & 52 & 19 & 80 & Cleared \\
6 & $\mathrm{~F}$ & 35 & 20 & 40 & No change \\
7 & $\mathrm{~F}$ & 23 & 11 & 70 & No change \\
8 & $\mathrm{~F}$ & 61 & 53 & 40 & Cleared \\
9 & $\mathrm{M}$ & 53 & 32 & 70 & Improved \\
10 & $\mathrm{M}$ & 29 & 17 & 80 & Cleared \\
11 & $\mathrm{M}$ & 30 & 15 & 90 & Improved \\
12 & $\mathrm{M}$ & 66 & 36 & 40 & No change \\
13 & $\mathrm{M}$ & 49 & 31 & 95 & No change \\
\hline
\end{tabular}

*Treatment stopped because of dyspepsia.

tErythema multiforme developed. unequivocally from taking the drug. The response was usually rapid, with lessened discomfort from the skin and a decrease in erythema.

Benoxaprofen produces a high incidence of cutaneous side effects, ${ }^{3}$ which are usually minor and include photosensitivity to long-wave intraviolet light. Initially we thought that benoxaprofen was exerting its effect by producing photosensitivity, but this hypothesis was untenable in view of the equal improvement in areas not exposed to light. It therefore seems likely that benoxaprofen acted by influencing the migration of inflammatory cells, particularly polymorphonuclear leucocytes, probably by inhibiting the production of chemotactic substances. A characteristic and consistent feature of the histology of psoriasis is a massive infiltration of polymorphonuclear neutrophilic leucocytes, often with the formation of Monro abscesses, which in the most severe cases are clinically evident as pustules. Whether or not these polymorphonuclear neutrophilic leucocytes are normal has been the subject of dispute for some years. What is known is that they have an active lipoxygenase system that produces 5-hydroperoxyeicosatetranenoic acid and derivatives, which have been christened "leukotrienes." One of these, leukotriene B4, is one of the most potent chemotactic substances yet identified and rivals the C5a component of complement in its activity. ${ }^{4}$ We suggest that benoxaprofen acted on psoriasis in the same way that it does in inflammatory conditions-by inhibiting the migration of leucocytes, in this case into the skin. It is known that polymorphonuclear neutrophilic leucocytes contain hydrolases that may stimulate epidermal cell proliferation ${ }^{5}$ and this supports the hypothesis that an abnormal response by polymorphonuclear neutrophilic leucocytes to a triggering factor might be the initiating event in psoriatic lesions.

There may be a basic deficiency in the cyclo-oxygenase enzyme system in psoriasis. This leads to an overproduction of leukotrienes, inappropriate accummulation of polymorphonuclear neutrophilic leucocytes, and a secondary increase in epidermal cell proliferation.

Our findings show that benoxaprofen might have had an important place in the treatment of severe psoriasis but perhaps more importantly indicate the direction for research to produce drugs with a more consistent effect and to determine the underlying defect.

${ }^{1}$ Cashin CH, Dawson W, Kitchen FA. The pharmacology of benoxaprofen a new compound with anti-inflammatory activity apparently unrelated to inhibition of prostaglandin synthesis. 7 Pharm Pharmacol 1977;29: 330-6.

2 Walker JR, Dawson W. Inhibition of rabbit polymorphonuclear lipoxygenase activity by benoxaprofen. 7 Pharm Pharmacol 1979;31:778-82.

${ }^{3}$ Hindson C, Daymond T, Diffey B, Lawlor F. Side effects of benoxaprofen. Br Med f 1982;284:1368-9.

${ }^{4}$ Ford-Hutchinson AW. Leukotriene B4 and neutrophilfunction: a review. f $R$ Soc Med $1981 ; 74: 831-3$.

${ }^{5}$ Lazavus GS, Gilgor RS. Psoriasis, polymorphonuclear leukocytes and lithium carbonate. Arch Dermatol 1975;115:1183-4.

(Accepted 13 August 1982)

Department of Dermatology, University Hospital, Queen's Medical Centre, Nottingham NG7 2UH

B R ALLEN, MB, MRCP, consultan

S M LITTLEWOOD, MB, MRCP, senior registrar

\section{Muscle cramps during treatment with nifedipine}

Nifedipine, a calcium antagonist with strong vasodilating properties, is widely used in the treatment of angina and has recently been shown to be effective in some cases of cardiac failure and systemic hypertension. ${ }^{1} \mathrm{~A}$ low incidence of side effects has been reported. ${ }^{1}$ We describe three cases of severe muscle spasms in which the drug had to be discontinued owing to intolerable side effects.

\section{Case reports}

Case 1-A 67-year-old man with stable angina pectoris, hypertension, and old myocardial infarction was treated with nifedipine $30 \mathrm{mg} /$ day. Four months after starting the drug he complained of severe muscle cramps in both legs and later also in the hands. Nifedipine was discontinued and after 24 hours the pain disappeared. Rechallenge with nifedipine after informed consent provoked the same symptoms after 48 hours. The drug was discontinued and six months later no muscle cramps had occurred. 
Case 2-A 56-year-old man suffered severe unstable angina three months after an inferior myocardial infarction. Treatment with propranolol 160 $\mathrm{mg} /$ day and isocardide dinitrate $60 \mathrm{mg} /$ day was ineffective, and nifedipine $40 \mathrm{mg} /$ day was added to the regimen. Three days later severe muscle cramps occurred in both legs and hands. The pain occurred only at night, the patient being asymptomatic during the day. The drug was discontinued and the cramps resolved. After a week the drug was readministered and the pain reappeared within 24 hours. The drug was again discontinued and the patient referred for surgery.

Case 3-A 73-year-old man with severe ischaemic heart disease and old myocardial infarction was referred to the outpatient clinic with severe stable angina. Treatment with isocardide dinitrate $80 \mathrm{mg} /$ day and propranolol $240 \mathrm{mg} /$ day was ineffective and nifedipine $30 \mathrm{mg} /$ day was begun. He felt better for two weeks but then began to complain of severe muscle cramps in both legs during the day and night, which necessitated discontinuation of the drug, with dramatic relief from pain. He died a month later after a myocardial infarction.

\section{Comment}

Serious underlying side effects due to nifedipine rarely occur. ${ }^{1}$ They are more common at the start of treatment, usually transient, and in most cases mild. The most common side effects are headache, facial flush, a sensation of heat, dizziness, nausea, and fatigue. In a therapeutic evaluation of 5000 patients none complained of muscle spasm. ${ }^{1}$ In two other patients treated with nifedipine muscle cramps resolved when the drug was stopped. ${ }^{2}$

In the three patients reported here the drug was stopped; rechallenge in two cases provoked the symptoms.

${ }^{1}$ Hashimoko K, Kimvra E, Kotayashi T, eds. First international Adalat symposium: new therapy of ischaemic heart disease. Tokyo: University of Tokyo Press, 1975.

2 Antman E, Muller J, Goldberg S. Nifedipine therapy for coronary spasm. $N$ Engl F Med 1980;302:1269-73.

(Accepted 13 August 1982)

Department of Cardiology, Lady Davis Carmel Hospital, Haifa 34362, Israel

SHLOMO KEIDAR, MD, senior resident medical officer

CHEN BINENBOIM, MD, resident physician

AVRAHAM PALANT, MD, head, department of cardiology

\section{Postexertional hypotension: a valuable physical sign}

Measurement of blood pressure on standing up from the supine position to detect postural hypotension is a well-recognised manoeuvre to assess the adequacy of the circulating blood volume and cardiovascular reflexes. Even though exercise in the upright position is a more demanding test of the integrity of the cardiovascular homeostatic mechanisms, measurement of blood pressure during or immediately after exercise is not generally advocated in clinical practice. I believe that detection of postexertional hypotension may have important diagnostic and therapeutic implications.

\section{Case reports}

Blood pressure and pulse rate were measured after patients had rested supine for three minutes, after they had been standing erect for one minute, and when they were standing erect immediately after exercise. A hand-held anaeroid sphygmomanometer calibrated regularly against a standard mercury instrument was used with a Velcro fixed cuff for speed of application. Depending on the patient and the facilities available the exercise consisted of two-step exercise, walking up and down a flight of stairs, or running on the spot. The exercise was judged by the patient's response and stopped at the onset of tiredness or breathlessness. Care was taken to ensure that the patient's arm was hanging relaxed or well supported at heart level to avoid an isometric effect.

Case 1-A woman treated with psychotropic drugs and a diuretic for a personality disorder and hypertension was found to be severely hyponatraemic. Although she was not apparently dehydrated, her blood pressure was $120 / 80 \mathrm{~mm} \mathrm{Hg}$ supine, $110 / 64 \mathrm{~mm} \mathrm{Hg}$ erect, and $64 / 40 \mathrm{~mm} \mathrm{Hg}$ after exercise. This indicated salt and water depletion and she was treated appropriately, having been subjected to water restriction for presumed inappropriate secretion of antidiuretic hormone.
Case 2-A 69-year-old man with dizziness on playing tennis was found to have a blood pressure of $158 / 80 \mathrm{~mm} \mathrm{Hg}$ supine, $136 / 84 \mathrm{~mm} \mathrm{Hg}$ erect, and $100 / 66 \mathrm{~mm} \mathrm{Hg}$ after exercise. Idiopathic "postural" hypotension was eventually diagnosed; his symptoms and hypotension were certainly not postural.

Other cases-Several patients with congestive cardiac failure due to hypertensive heart disease treated with methyldopa and diuretics complained of weakness and breathlessness on exertion associated with postexertional hypotension. These symptoms improved and the hypotension disappeared when the dose of the drugs was reduced.

\section{Comment}

On dynamic exercise in healthy people systolic blood pressure reaches $200 \mathrm{~mm} \mathrm{Hg}$ with a smaller rise or no rise in diastolic pressure. ${ }^{1}$ When exercise stops the blood pressure dips transiently but then rises again and slowly falls to normal. Any fall in systolic blood pressure below the resting value half a minute after exercise is probably abnormal. ${ }^{2}$

The sympathetic nervous system mediates reflexes that maintain blood pressure in the presence of skeletal muscle vasodilatation and are called into play at the onset of exercise. ${ }^{3}$ The importance of these early reflex responses is highlighted by the pronounced fall in blood pressure regularly observed after only trivial exercise in patients taking adrenergic-neurone-blocking drugs. Impairment of cardiovascular homeostatic mechanisms thus seems to be demonstrable with short spells of uncontrolled mild exercise as described above. Assessment is feasible in all but the most disabled patients even in domiciliary practice.

The sympathetic nervous system plays an especially important part in hypovolaemic states, ${ }^{4}$ and in these circumstances exercise testing has been of particular value. Heart responses have not proved helpful in assessing the relative contribution of neural and blood-volume abnormalities to postexertional falls in blood pressure.

The symptoms associated with postexertional hypotension are often not the classical ones of presyncope or frank syncope ${ }^{5}$ but may, as noted above, consist of tiredness, heavy legs, and breathlessness. Careful measurement of the erect systolic blood pressure before and after dynamic exercise may help in assessing patients with suspected hypovolaemia, neurodepressant drug effects, or otherwise unexplained symptoms on exertion.

${ }^{1}$ Holmgren A. Circulatory changes during muscular work in man. Scand $\mathcal{f}$ Clin Lab Invest 1956;8,suppl 24:1-97.

2 Korner PI. The normal human blood pressure during and after exercise, with some related observations on changes in the heart rate and the blood flow in the limbs. Aust $\mathcal{F}$ Exp Biol Med Sci 1952;30:375-84.

${ }^{3}$ Buskirk ER. Cardiovascular adaptation to physical effort in healthy men. In: Naughton JP, Hellerstein $\mathrm{HK}$, eds. Exercise testing and exercise training in coronary heart disease. New York: Academic Press, 1973 : 23-31.

${ }^{4}$ Anderson RJ, Linas SL. Sodium depletion states. In: Brenner BM, Stein JH, eds. Sodium and water homeostasis. New York: Churchill Livingstone, 1978:154-77.

5 Judson WE. Hypotension; physiologic mechanisms and treatment. Med Clin North Am 1953;37:1313-39.

(Accepted 24 August 1982)

Whittington Hospital, London N19 5NF

B I HOFFBRAND, DM, FRCP, consultant physician

\section{Nutritional rickets in Rastafarian children}

Nutritional rickets in Asian children living in the United Kingdom has been the subject of much discussion during the past 20 years and increasingly in the past decade. We diagnosed nutritional rickets in four black Rastafarian children and believe we have identified another population at risk.

\section{Case reports}

Case 1-An 11-month-old girl presented with a painful arm. $X$-ray examination of the wrist showed classic changes of rickets. Serum calcium 